Revista Científica do Corpo de Bombeiros Militar de Pernambuco

XVIII Seminário Nacional de Bombeiros - Foz do Iguaçu PR

Vol.04 No11 - Edição Especial XVIII SENABOM - ISSN 2359-4829

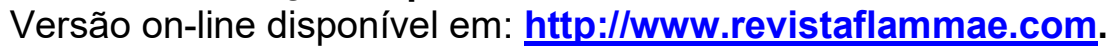

\title{
ÓBITOS POR AFOGAMENTO EM SANTA CATARINA: UM PROBLEMA
}

\author{
ALÉM-MAR \\ DEATH FOR DROWNING IN SANTA CATARINA: A PROBLEM BEYOND SEA
}

Rafael Manoel José ${ }^{1}$

\begin{abstract}
Resumo
Esta pesquisa tem como objetivo geral, analisar os óbitos por afogamento ocorridos em Santa Catarina entre os dias $1^{\circ}$ de janeiro de 1989 a 31 de dezembro de 2015 e como objetivos específicos: (I) classificar os 295 municípios catarinenses quanto ao índice relativo de óbitos por afogamento, (II) destacar os 10 municípios com os maiores índices para cada Batalhão de Bombeiro Militar (BBM), (III) relacionar os índices relativos dos municípios tabelados com (a) os números absolutos de casos, e (b) com os municípios aonde há quartel do CBMSC e; (IV) definir, para cada BBM, os municípios catarinenses mais propensos para uma intensificação das atividades preventivas relacionadas aos óbitos por afogamento. Verificou-se que os índices relativos de óbitos por afogamento variam ao longo de todo o estado e, com a exceção do $12^{\circ}$ e $14^{\circ} \mathrm{BBM}$, todos os demais apresentam municípios propensos para a intensificação de atividade preventiva na área em questão, destacando-se, o $7^{\circ} \mathrm{BBM}$.
\end{abstract}

Palavras-chave: Óbito. Afogamento. Santa Catarina. CBMSC.

\begin{abstract}
This research aims at analyzing the occurrence of deaths by drowning in Santa Catarina (SC) between January 1st, 1989 and December 31st, 2015. Specifically, it aims at (I) classifying the 295 cities of SC regarding the relative rate of drowning deaths, (II) highlighting the 10 cities with the highest rates in each Battalion jurisdiction (BBM), (III) relating the cities relative rates with (a) the absolute numbers of cases, and (b) the cities with a SC Military Fire Station and; (IV) defining for each BBM jurisdiction the cities that should receive more attention in terms of preventive activities related to drowning deaths. The results pointed out that the relative rates of drowning deaths in SC vary throughout the state and all the cities, mainly 7th BBM jurisdiction, should receive more attention in terms of preventive activities, except the 12th and 14th BBM jurisdictions.
\end{abstract}

Key words: Death. Drowning. Santa Catarina. CBMSC.

$1-2^{\circ}$ Tenente do Corpo de Bombeiros Militar de Santa Catarina. Comandante do Pelotão de Bombeiros Militar de Fraiburgo. Graduado no curso de Licenciatura Plena em Educação Física pela Universidade Federal de Santa Catarina-UFSC (2008), Especialista em Gestão de Defesa Civil pela Universidade de São José-USJ (2010), Especialista em Gestão de Riscos e Eventos Críticos pelo Corpo de Bombeiros Militar de Santa Catarina-CBMSC (2016). E-mail: rmanoel@.cbm.sc.gov.br 


\section{INTRODUÇÃO}

Neste trabalho será feita uma breve análise teórica envolvendo o conceito de afogamento e seus graus, de acordo com sua gravidade. Neste caso, o destaque fica para o fato de que afogamento não necessariamente é sinônimo de óbito. Serão analisadas diversas pesquisas estatísticas sobre o índice de óbitos por afogamento levando-se em conta a população de determinados locais, ou seja, o índice relativo. Estas análises servem como base para o objetivo geral desta pesquisa, qual seja, analisar os óbitos por afogamento ocorridos em Santa Catarina entre os dias $1^{\circ}$ de janeiro de 1989 a 31 de dezembro de 2015. Tem-se como objetivos específicos: (I) classificar os 295 municípios catarinenses quanto ao citado índice, de modo geral, separando-os por determinadas áreas de atuação do CBMSC; (II) destacar os 10 municípios com os maiores índices para cada BBM; (III) relacionar os índices relativos dos municípios tabelados com (a) os números absolutos de casos, destacando-se os municípios com mais de um caso por ano, e (b) com os municípios aonde há quartel do CBMSC e; (IV) definir, para cada BBM, os municípios catarinenses mais propensos para uma intensificação das atividades preventivas relacionadas aos óbitos por afogamento. Para tanto, será dado destaque aos municípios que apresentarem, ao menos, 2 dos três quesitos a seguir: 1 índice relativo de óbitos por afogamento igual ou superior a 5;2 - número absoluto de óbitos por afogamento igual ou superior a 27 (ou seja, igual ou superior a 1 por ano) e; 3 - possuir OBM. A justificativa para a realização desta pesquisa se faz por serem os óbitos por afogamento ocorrências que não deixam de acontecer em território catarinense, apesar de todas as práticas preventivas que buscam este fim. Neste sentido, considerando o elevado potencial turístico de Santa Catarina, principalmente no verão e na região litorânea, levanta-se a seguinte problemática: quais os municípios catarinenses mais vulneráveis aos óbitos por afogamento? Para alcançar a resposta a esta questão, será realizada pesquisa aplicada, exploratória e descritiva envolvendo levantamento bibliográfico, documental e a análise de dados. É uma pesquisa, predominantemente, quantitativa e de cunho estatístico, haja vista a análise de dados fornecidos pelo Estado- 
Revista Científica do Corpo de Bombeiros Militar de Pernambuco

XVIII Seminário Nacional de Bombeiros - Foz do Iguaçu PR

Vol.04 No11 - Edição Especial XVIII SENABOM - ISSN 2359-4829

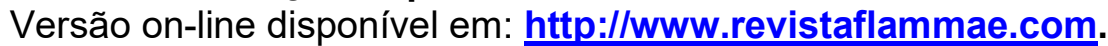

Maior Geral do CBMSC (BM-2 - informações), oriundos dos Institutos Gerais de Perícia do Estado de Santa Catarina (CBMSC, 2017). Porém, também apresenta cunho qualitativo, em detrimento aos trabalhos preventivos que desta pesquisa poderão surgir.

\section{AFOGAMENTO}

\section{Conceito, classificação e índices relativos de óbitos por afogamento}

Fisher Júnior, Souza \& Maia (1982), apresentam uma das mais antigas pesquisas científicas encontradas realizadas em Santa Catarina sobre o tema afogamento e o conceituam como sendo "a morte por asfixia, resultante da submersão na água (GRAVES, S.A, 1980 apud FISHER JÚNIOR, SOUZA \& MAIA, 1982). Na época, os citados autores já destacavam que, entre os maiores danos causados pelo afogamento estão a hipoxemia arterial e a acidose metabólica, além da possibilidade de contaminação do organismo por água poluída. Destacam também que, nos casos de afogamento em água salgada, pode ocorrer hipovolemia, o que tornaria necessária a reposição de líquidos ao afogado. Por sua vez, nos casos de afogamento em água doce, pode ocorrer hipervolemia, necessitando-se de um aumento na diurese. Indo de encontro ao conceito apresentado pelos próprios autores, dos 10 casos de afogamento relacionados a esta pesquisa, apenas 1 foi a óbito (FISHER JÚNIOR, SOUZA \& MAIA, 1982).

Pesquisas posteriores a esta conceituam afogamento como sendo um trauma (WHO, 2006, apud SOMMARIVA, 2006) caracterizado pelo processo de experiência de comprometimento respiratório por submersão ou imersão num líquido (VAN BEECK et al, 2005, citados por SOMMARIVA, 2006 e por BMJ Best Practice, 2017). Quanto aos índices, Sommariva cita que, em 1998, o índice de óbitos relativo por afogamento no Brasil foi de 4,4 para cada 100.000 habitantes (SZPILMAN, 2000, apud SOMMARIVA, 2006). Verifica com o resultado de sua pesquisa que, na região da 
Revista Científica do Corpo de Bombeiros Militar de Pernambuco

XVIII Seminário Nacional de Bombeiros - Foz do Iguaçu PR

Vol.04 N011 - Edição Especial XVIII SENABOM - ISSN 2359-4829

Versão on-line disponível em: http://www.revistaflammae.com.

grande Florianópolis ${ }^{1}$, este índice foi de 3,6 no ano de 2005, valor inferior ao coeficiente de mortalidade global por afogamento em 1990, que foi de 5,04 (MURRAY E LOPEZ, 1997, apud SOMMARIVA, 2006) e superior ao índice do município de Curitiba no ano de 2003, que foi de 2,8 (PREFEITURA DE CURITIBA, 2006, APUD, SOMMARIVA, 2006). Nesta mesma pesquisa, Sommariva cita a faixa etária de 30 a 39 anos de idade como a mais vulnerável frente às mortes por afogamento, a qual apresentou 21\% dos óbitos por afogamento ocorridos em Florianópolis de 1991 a 2005, óbitos estes distribuídos em todos os meses do ano (2006). Somariva identificou que $34 \%$ dos óbitos estavam relacionados ao consumo de álcool e cita que "uma concentração sanguínea de $0,1 \mathrm{~g} / 100 \mathrm{ml}$ aumenta em 10 vezes o risco de morte nesta situação" (DRISCOLL, HARRISON \& STEENKAMP, 2004, apud SOMMARIVA, 2006 , p. 17). Quanto à origem das vítimas, Sommariva identificou que $72 \%$ delas eram da região da grande Florianópolis, porém, não especificando o município de procedência de cada uma delas. Quanto às questões preventivas, Sommariva cita que "lições de natação não são estratégias efetivas de prevenção em crianças com menos de 04 anos, podendo até ser fator de risco encorajando a criança a se expor mais a água" (apud THE WORLD CONGRESS ON DROWNING AMSTERDAM, 2002; NGUYEN \& WARDA, 2003).

Por sua vez, Rodrigo Thadeu de Araújo, um dos pesquisadores que tratou sobre o tema em regiões não litorâneas do Brasil, identificou o número de 2,44 óbitos para cada 100.000 habitantes por ano, na região de Ribeirão Preto - SP, pesquisa a qual envolveu dados de 2001 a 2004, totalizando 89 casos de óbitos por afogamento, divididos em 17 municípios, envolvendo uma população de, aproximadamente, 910.000 habitantes (ARAÚJO, 2007). Na citada pesquisa, Araújo identificou que ocorreram óbitos por afogamento em todos os meses do ano (2007). Quanto à faixa etária, o destaque da pesquisa de Araújo ficou para a de 30 a 39 anos com 20,2\% dos casos

\footnotetext{
${ }^{1} \mathrm{Na}$ época desta pesquisa, a região da Grande Florianópolis era integrada pelos seguintes municípios: Águas Mornas, Alfredo Wagner, Angelina, Anitápolis, Antônio Carlos, Biguaçu, Canelinha, Florianópolis, Governador Celso Ramos, Major Gercino, Palhoça, Paulo Lopes, Porto Belo, Rancho Queimado, Santo Amaro da Imperatriz, São Bonifácio, São João Batista, São José, São Pedro de Alcântara e Tijucas.
} 
(2007). Na ocasião, Araújo comparava o índice de 2,44 óbitos para cada 100.000 habitantes por ano ao índice da cidade do Rio de Janeiro, que era de 4,1 (SZPILMAN e CRUZ FILHO, 2002; apud ARAÚJO, 2007). Araújo cita também, a importância do histórico da ocorrência e que no seu estudo não foi identificado se as vítimas sabiam nadar nem se estavam sob efeito de álcool e assim encerra sua discussão:

\begin{abstract}
O ser humano é filho da cultura. Reproduz padrões de sentir, pensar e de agir no mundo. Todos herdados na forma de crenças e valores. Assim, o homem é fruto de idéias tradicionais que influenciam a percepção e comportamento. Recebe uma herança cultural negligente em relação aos cuidados com a água. Faltam cuidados para que a água não inunde casas, não seja irracionalmente e predatoriamente poluída e também, não seja a causa desse mal que cria sofrimento na comunidade, o afogamento.

O número de afogamentos pode ser reduzido na Região de Ribeirão Preto. A sociedade está submersa numa cultura de imprevidência que só pode ser mudada com o esforço inteligente e sistemático da educação. Uma educação que com o estímulo da informação e reflexão, desenvolva novos valores humanos de cuidado e prudência. Afinal prevenir é melhor que resgatar corpos (ARAÚJO, 2007, p. 49).
\end{abstract}

De acordo com os estudos mais recentes de Szpilman (datado de 2017 mas, sobre os números de 2015), no mundo, o índice de óbitos por afogamento a cada 100.000 habitantes-ano é de 8,5; na América do Sul, de 3,3 e, no Brasil, de 2,9. A 2a região brasileira de menor índice é o sul, com 2,89 enquanto o norte figura com um índice de 5,61 mortos por afogamento para cada 100.00 habitantes ao ano. Segundo Szpilman, Santa Catarina apresenta índice de 3,32.

De acordo com esta mesma fonte, $49 \%$ dos óbitos por afogamento no Brasil ocorrem na faixa etária entre 1 e 29 anos. Dentro destas faixas etárias, o afogamento figura entre a $2^{\mathrm{a}}$ e a $5^{\mathrm{a}}$ causa de morte no país. Os gastos envolvidos com cada um destes traumas fatais e a perda na produção econômica, para o país, com cada um destes óbitos custa cerca de R\$210.000,00 (SZPILMAN, 2017). Para a família dos que se foram, é uma perda incalculável. Apesar dos estudos, o citado autor estima que 94\% da informação dos incidentes aquáticos em nosso país seja desconhecida. Szpilman cita também que, de acordo com estimativas da Sociedade Brasileira de Salvamento Aquático (SOBRASA), apenas 15\% dos óbitos por afogamento no Brasil ocorrem em praias oceânicas. A demais, $75 \%$ dividem-se entre rios com correnteza, represas, 
Revista Científica do Corpo de Bombeiros Militar de Pernambuco

XVIII Seminário Nacional de Bombeiros - Foz do Iguaçu PR

Vol.04 No11 - Edição Especial XVIII SENABOM - ISSN 2359-4829

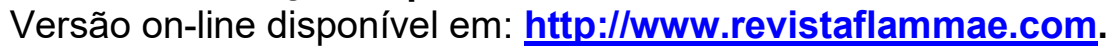

remansos de rios, lagoas, inundações, baías, cachoeiras e córregos. Estes são os chamados ambientes naturais. $8,5 \%$ dos casos ocorrem em ambientes não naturais, dentre eles: banheiros, caixas de água, baldes e similares, galerias de águas fluviais, piscinas e poços. Os 1,5\% restantes são relacionados ao transporte com embarcações (SZPILMAN, 2017).

Quanto à classificação, os casos de afogamento são divididos em graus, indo do grau 1 ao grau 6 sendo aquele o mais brando e este o mais grave, caracterizados conforme tabela a seguir:

Tabela 1 - Características dos graus de afogamento.

\begin{tabular}{|c|c|}
\hline Grau de afogamento & Características da vítima \\
\hline 1 & Tosse sem espuma na boca ou nariz \\
\hline 2 & Pouca espuma na boca/nariz \\
\hline 3 & Grande quantidade de espuma na boca/nariz, COM pulso radial palpável \\
\hline 4 & Grande quantidade de espuma na boca/nariz, SEM pulso radial palpável \\
\hline 5 & Parada Respiratória, com pulso carotídeo ou sinais de circulação presente \\
\hline 6 & \\
\hline
\end{tabular}

Fonte: CBMSC (2018b)

Considerando a tabela 1 , destaca-se que o afogamento não necessariamente caracteriza um óbito, ainda que, de acordo com a sua gravidade poderá levar a ele.

\section{Índices relativos de óbitos por afogamento em Santa Catarina de 1989 a} 2015: resultados e discussões

A partir da identificação da maneira adotada para a realização da análise dos índices de óbitos por afogamento no Brasil (SZPILMAN, 2017), foi realizada análise dos dados de cada um dos 295 municípios catarinenses entre os dias $1^{\circ}$ de janeiro de 1989 a 31 de dezembro de 2015. Apresenta-se a seguir tabela/legenda para a classificação do índice relativo de óbitos por afogamento para cada 100.000 habitantes a qual servirá como referência para a interpretação das demais tabelas e figuras aqui elaboradas: 
Revista Científica do Corpo de Bombeiros Militar de Pernambuco

XVIII Seminário Nacional de Bombeiros - Foz do Iguaçu PR

Vol.04 No11 - Edição Especial XVIII SENABOM - ISSN 2359-4829

Versão on-line disponível em: http://www.revistaflammae.com.

Tabela 2: Legenda para identificação do índice relativo de óbitos por afogamento para cada 100.000 habitantes.

\begin{tabular}{|c|c|}
\hline \multicolumn{2}{|c|}{ ÍNDICE RELATIVO DE ÓBITOS POR AFOGAMENTO } \\
\hline COR & VALOR \\
\hline VERMELHO & IGUAL OU MAIOR QUE 5 \\
\hline LARANJA & DE 4 A 4,99 \\
\hline AMARELO & DE 3 A 3,99 \\
\hline CIANO & DE 2 A 2,99 \\
\hline BRANCO & MENOR QUE 2 \\
\hline
\end{tabular}

Fonte: Do autor.

Destaca-se que, para a obtenção dos dados apresentados nas tabelas a seguir, não foi levada em conta a população flutuante de nenhum município, em nenhuma época do ano (o que, reduziria estes índices) e sim, a população estimada pelo IBGE para o ano de 2017 (IBGE, 2017).

Neste sentido, apresenta-se a seguir o mapa de SC, destacando-se áreas específicas e o índice relativo de afogamento de cada uma delas: 
Revista Científica do Corpo de Bombeiros Militar de Pernambuco

XVIII Seminário Nacional de Bombeiros - Foz do Iguaçu PR

Vol.04 N011 - Edição Especial XVIII SENABOM - ISSN 2359-4829

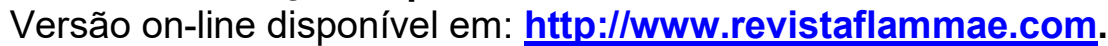

Figura 1: Mapa de Santa Catarina identificando o índice relativo de óbitos por afogamento em cada Região de Bombeiros Militar (RBM) desde o dia $1^{\circ}$ de janeiro de 1989 até 31 de dezembro de 2015.

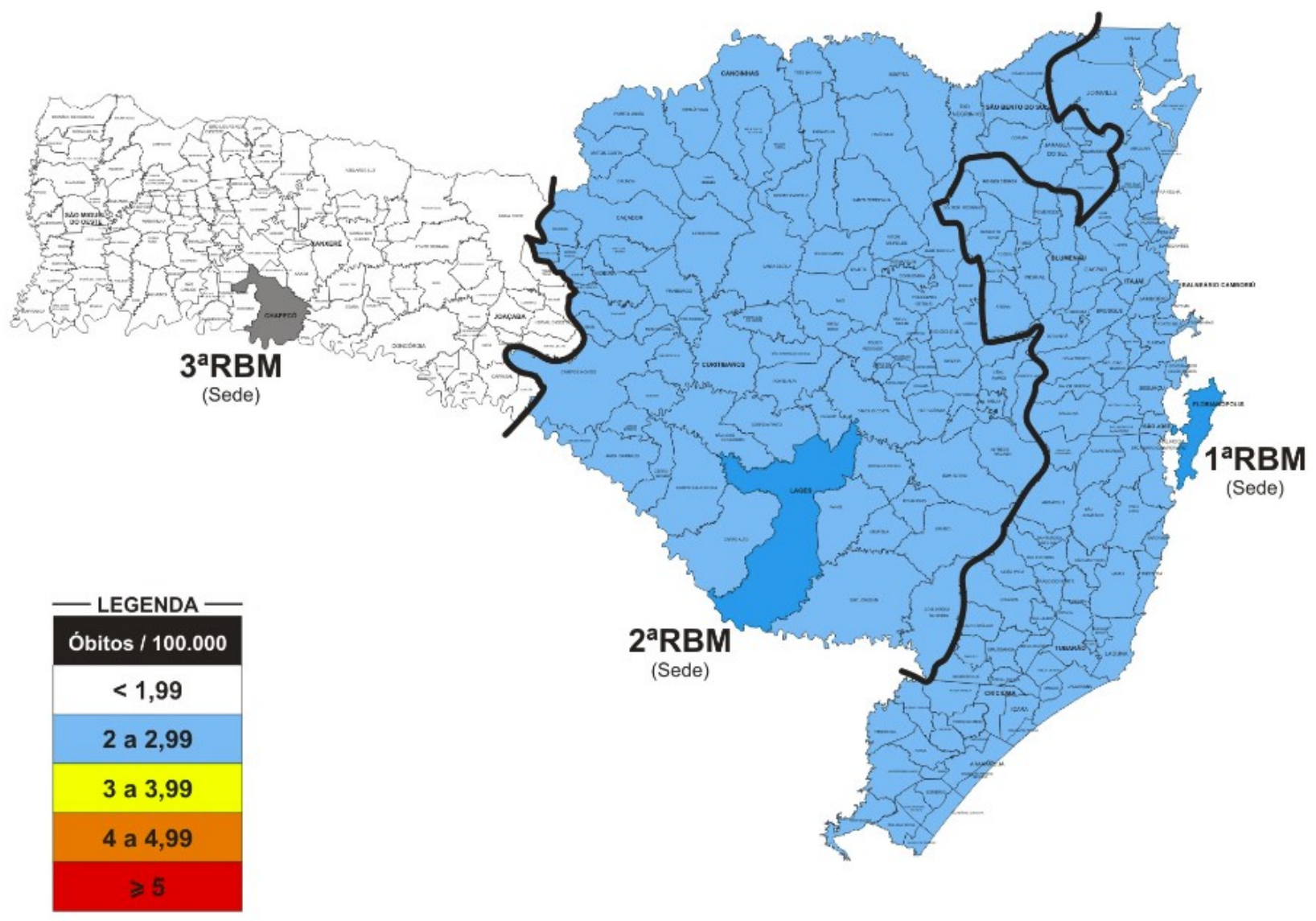

Fonte: José e Kaffer, 2018.

No que tange a figura 1, para a $1^{\mathrm{a}} \mathrm{RBM}$, integrada por 7 Batalhões de Bombeiros Militar (BBBBMM), totalizando 103 municípios, o índice obtido foi de 2,7. Por sua vez o número absoluto de casos foi de 3.361, o que representa, aproximadamente, 69,6\% dos 4.831 casos para o período estudado. Dentre os 103 municípios da $1^{\mathrm{a}} \mathrm{RBM}$, o CBMSC está presente em 67 deles (aproximadamente, $65 \%)^{2}$.

Quanto à $2^{\mathrm{a}} \mathrm{RBM}$, integrada por $3 \mathrm{BBBBMM}$, totalizando 87 municípios, $\mathrm{o}$ índice obtido foi de 2,57. O número absoluto de óbitos por afogamento foi de 917

2 Em 10 destes municípios, há quarteis do CBMSC destinados somente ao Serviço de Atividades Técnicas (SAT). 
Revista Científica do Corpo de Bombeiros Militar de Pernambuco

XVIII Seminário Nacional de Bombeiros - Foz do Iguaçu PR

Vol.04 N011 - Edição Especial XVIII SENABOM - ISSN 2359-4829

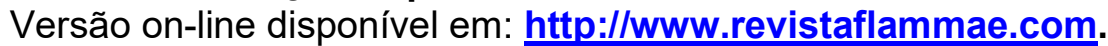

(aproximadamente, 19\% do total). Nos 87 municípios que integram a 2 $2^{\mathrm{a} B M}$, há OBM em 33 (aproximadamente, 38\%) ${ }^{3}$.

Por sua vez, tratando-se da $3^{\mathrm{a}}$ RBM, integrada por 4 BBBBMM, integrados por 105 municípios, o índice relativo de óbitos por afogamento foi de 1,92. Nesta região, foram 553 casos, ou seja, aproximadamente, 11,4\%. Dentre estes municípios, há OBM em 31 deles $(29,5 \%)$.

Analisando-se, especificamente cada BBM, tem-se o mapa a seguir:

Figura 2: Mapa de Santa Catarina identificando o índice relativo de óbitos por afogamento em cada BBM desde o dia $1^{\circ}$ de janeiro de 1989 até 31 de dezembro de 2015.

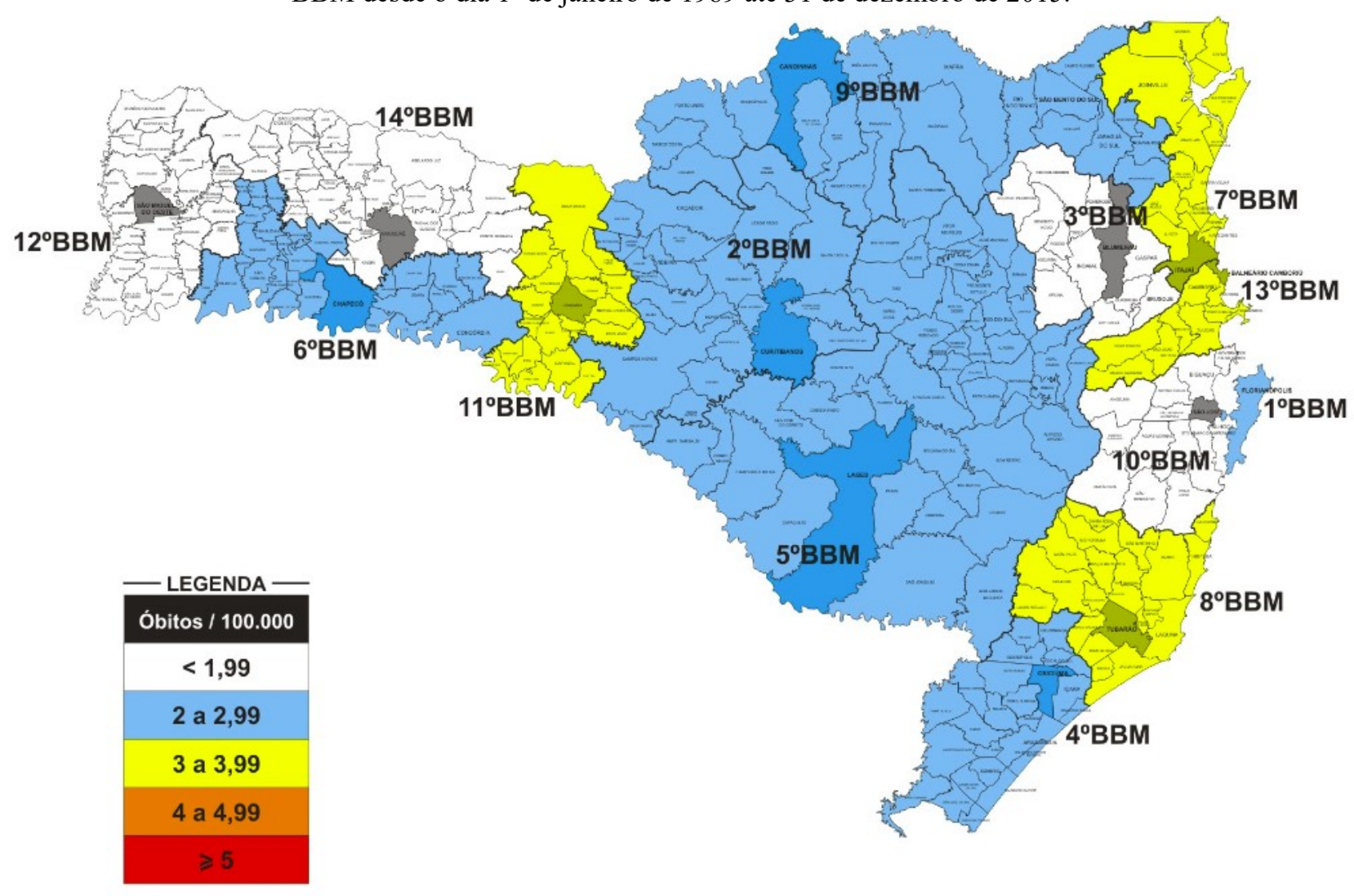

Fonte: José e Kaffer, 2018.

3 Em 1 destes municípios, há quartel do CBMSC destinado somente ao SAT. 
Revista Científica do Corpo de Bombeiros Militar de Pernambuco

XVIII Seminário Nacional de Bombeiros - Foz do Iguaçu PR

Vol.04 No11 - Edição Especial XVIII SENABOM - ISSN 2359-4829

Versão on-line disponível em: http://www.revistaflammae.com.

Com base na figura 2, observa-se que ao analisar-se determinadas regiões com maiores especificidades, os índices relativos passam a apresentar-se de uma outra forma, tendo-se, assim, a seguinte classificação para cada BBM:

Tabela 3: Classificação, em ordem decrescente, dos índices relativos de óbitos por afogamento dos 14 Batalhões de Bombeiro Militar (BBBBMM) do CBMSC.

\begin{tabular}{|c|c|c|c|}
\hline Classificação & BBM & \begin{tabular}{|c|} 
Número absoluto de \\
óbitos por afogamento \\
de $1^{\circ}$ de janeiro de1989 a \\
31 de dezembro de 2015
\end{tabular} & $\begin{array}{c}\text { Índice relativo de óbitos } \\
\text { por afogamento a cada } \\
100.000 \text { habitantes por } \\
\text { ano no período }\end{array}$ \\
\hline $1^{\mathrm{o}}$ & 13º (BALNEÁRIO CAMBORIÚ) & 430 & 3,83 \\
\hline $2^{\circ}$ & $7^{\circ}$ (ITAJAÍ) & 1313 & 3,53 \\
\hline $3^{\circ}$ & $8^{\circ}$ (TUBARÃO) & 375 & 3,28 \\
\hline $4^{\circ}$ & $11^{\circ}(\mathrm{JOAÇABA})$ & 122 & 3,01 \\
\hline $5^{\circ}$ & $5^{\circ}$ (LAGES) & 453 & 2,81 \\
\hline $6^{\circ}$ & $2^{\circ}$ (CURITIBANOS) & 252 & 2,73 \\
\hline $7^{\circ}$ & $1^{\circ}$ (FLORIANÓPOLIS) & 353 & 2,69 \\
\hline $8^{\circ}$ & $4^{\circ}$ (CRICIÚMA) & 369 & 2,31 \\
\hline $9^{\circ}$ & $6^{\circ}$ (CHAPECÓ) & 265 & 2,17 \\
\hline $10^{\circ}$ & $9^{\circ}$ (CANOINHAS) & 212 & 2,06 \\
\hline $11^{\circ}$ & $10^{\circ}$ (SÃO JOSÉ) & 270 & 1,82 \\
\hline $12^{\circ}$ & $12^{\circ}$ (SÃO MIGUEL DO OESTE) & 85 & 1,38 \\
\hline $13^{\circ}$ & $14^{\circ}$ (XANXERÊ) & 81 & 1,26 \\
\hline $14^{\circ}$ & $3^{\circ}$ (BLUMENAU) & 251 & 1,21 \\
\hline $\mathrm{SC}$ & & 4831 & 2,56 \\
\hline
\end{tabular}

Fonte: Do autor.

Para esta análise, o BBM que aparece representando uma maior vulnerabilidade é o, litorâneo, da região centro-norte, $13^{\circ} \mathrm{BBM}$, sediado em Balneário Camboriú. Logo a seguir aparece o $7^{\circ} \mathrm{BBM}$, também litorâneo, do qual fazem parte seis dos dez municípios mais vulneráveis de SC para os casos em questão, conforme será apresentado na Tabela 4. Em terceiro lugar, figura o $8^{\circ} \mathrm{BBM}$, sediado em Tubarão e 
Revista Científica do Corpo de Bombeiros Militar de Pernambuco

XVIII Seminário Nacional de Bombeiros - Foz do Iguaçu PR

Vol.04 No11 - Edição Especial XVIII SENABOM - ISSN 2359-4829

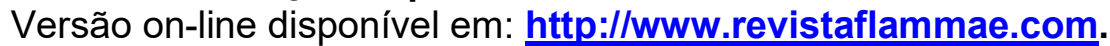

integrado pelos municípios do litoral-sul de SC. Fechando os BBBBMM com índices entre 3,99 e 3, aparece pela primeira vez na tabela BBM que não integra a região litorânea, qual seja, o $11^{\circ} \mathrm{BBM}$, sediado em Joaçaba.

Com índices entre 2,99 e 2, aparecem, respectivamente, os BBBBMM sediados em Lages ( $\left.5^{\circ} \mathrm{BBM}\right)$, Curitibanos ( $\left.{ }^{\circ} \mathrm{BBM}\right)$, Florianópolis ( $\left.{ }^{\circ} \mathrm{BBM}\right)$, Criciúma $\left(4^{\circ}\right.$ BBM), Chapecó ( $\left.6^{\circ} \mathrm{BBM}\right)$ e Canoinhas ( $\left.9^{\circ} \mathrm{BBM}\right)$.

Por fim, com os menores índices, aparecem os BBBBMM sediados em São José $\left(10^{\circ} \mathrm{BBM}\right)$, São Miguel do Oeste (12 $\left.\mathrm{BBM}\right)$, Xanxerê $\left(14^{\circ} \mathrm{BBM}\right)$ e Blumenau $\left(3^{\circ}\right.$ BBM), com índices inferiores a 2 .

Apesar de BBBBMM litorâneos ocuparem as três primeiras posições na lista, observa-se aqui índices superiores para BBBBMM não-litorâneos, como é o caso do $11^{\circ}$ BBM (sediado em Joaçaba), $5^{\circ}$ BBM (sediado em Lages) e $2^{\circ}$ BBM (sediado em Curitibanos) quando comparados, por exemplo, ao $1^{\circ} \mathrm{BBM}$ (Florianópolis). Do mesmo modo, $6^{\circ} \mathrm{BBM}$ (sediado em Chapecó) e $9^{\circ} \mathrm{BBM}$ (sediado em Canoinhas) aparecem com índices superiores ao do, litorâneo, $10^{\circ} \mathrm{BBM}$ (sediado em São José).

Por sua vez, analisando-se especificamente cada município, fica assim a apresentação dos índices em estudo: 
Revista Científica do Corpo de Bombeiros Militar de Pernambuco

XVIII Seminário Nacional de Bombeiros - Foz do Iguaçu PR

Vol.04 N011 - Edição Especial XVIII SENABOM - ISSN 2359-4829

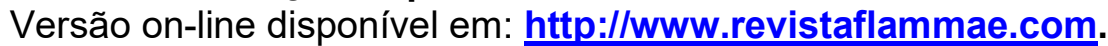

Figura 3: Mapa de Santa Catarina identificando o índice relativo de óbitos por afogamento em cada município do Estado desde o dia $1^{\circ}$ de janeiro de 1989 até 31 de dezembro de 2015.

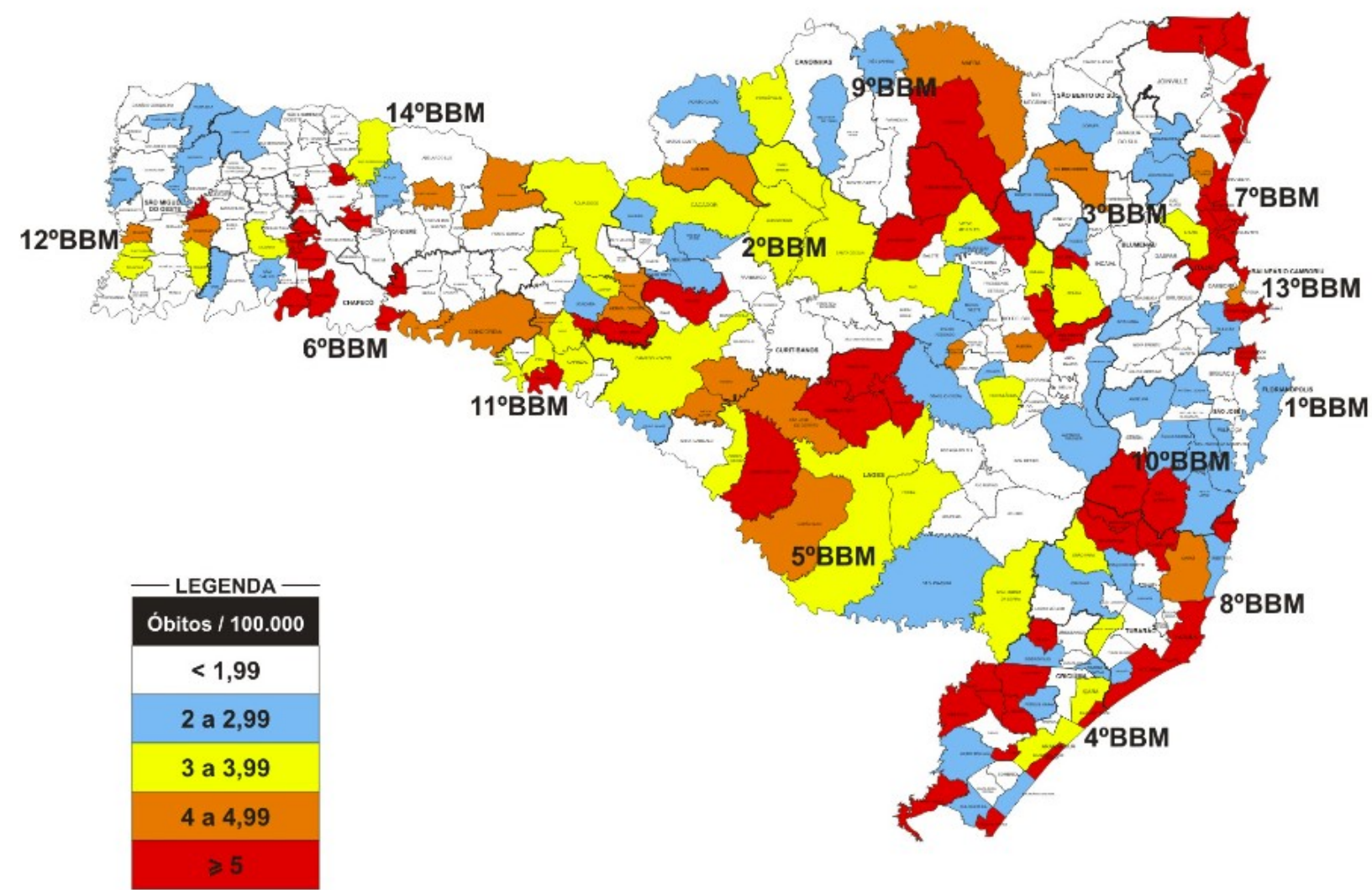

Fonte: José e Kaffer, 2018.

E é com este último mapa que analisa-se com maior clareza a situação de cada município. Assim sendo, inicia-se esta análise minuciosa apresentando-se os 10 municípios mais suscetíveis aos óbitos por afogamento em Santa Catarina, levando-se em conta o período analisado e a população de cada município: 
Revista Científica do Corpo de Bombeiros Militar de Pernambuco

XVIII Seminário Nacional de Bombeiros - Foz do Iguaçu PR

Vol.04 No11 - Edição Especial XVIII SENABOM - ISSN 2359-4829

Versão on-line disponível em: http://www.revistaflammae.com.

Tabela 4: Classificação, em ordem decrescente, dos 10 municípios com os maiores índices relativos de óbitos por afogamento do Estado de Santa Catarina.

\begin{tabular}{|c|c|c|c|c|c|}
\hline Classificação & Município & BBM & $\begin{array}{l}\text { Possui } \\
\text { OBM }\end{array}$ & \begin{tabular}{|c|} 
Número absoluto de \\
óbitos por afogamento \\
de $1^{\circ}$ de janeiro de1989 a \\
31 de dezembro de 2015
\end{tabular} & $\begin{array}{c}\text { Índice relativo de óbitos } \\
\text { por afogamento a cada } \\
100.000 \text { habitantes por ano } \\
\text { no período }\end{array}$ \\
\hline $1^{\circ}$ & Itapoá & $7^{\circ}$ & Sim & 91 & 17,41 \\
\hline $2^{\circ}$ & $\begin{array}{l}\text { Balneário Barra } \\
\text { do Sul }{ }^{4}\end{array}$ & $7^{\circ}$ & Sim-SAT & 47 & 16,87 \\
\hline $3^{\circ}$ & Passo de Torres & $4^{\circ}$ & Sim & 34 & 15,04 \\
\hline $4^{\circ}$ & $\begin{array}{l}\text { São Francisco } \\
\text { do Sul* }\end{array}$ & $7^{\circ}$ & Sim & 166 & 12,13 \\
\hline $5^{\circ}$ & Barra Velha* & $7^{\circ}$ & Sim & 85 & 11,33 \\
\hline $6^{\circ}$ & Penha* & $7^{\circ}$ & Sim-SAT & 85 & 10,15 \\
\hline $7^{\circ}$ & Bombinhas & $13^{\circ}$ & Sim & 51 & 10,14 \\
\hline $8^{\circ}$ & Marema & $14^{\circ}$ & Não & 5 & 9,72 \\
\hline $9^{\circ}$ & Paial & $6^{\circ}$ & Não & 4 & 9,39 \\
\hline $10^{\circ}$ & Garuva & $7^{\circ}$ & Sim & 44 & 9,32 \\
\hline
\end{tabular}

Fonte: Do autor.

Ao analisarmos a Tabela 4, podemos observar o destaque (negativo) para seis municípios da área do $7^{\circ} \mathrm{BBM}$, todos correspondentes à região do litoral Norte de Santa Catarina. Destes, somente Garuva não possui contato com o mar. Além deste, apenas outros dois municípios não-litorâneos aparecem na lista, quais sejam, Marema e Paial, estes dois, inclusive, apresentando números absolutos de casos relativamente pequenos e sendo os dois únicos da lista nos quais não há $\mathrm{OBM}^{5}$.

Além das dez cidades listadas à cima, 57 dos 295 municípios catarinenses (cerca de $20 \%$ ) apresentaram índice relativo de óbitos por afogamento igual ou superior a $5^{6}$.

De forma individual, analisando-se os municípios de cada BBM, foram encontrados os resultados a seguir. A começar pelo $1^{\circ} \mathrm{BBM}$, o qual é integrado por um único município, Florianópolis, o índice relativo de óbitos por afogamento para cada

\footnotetext{
${ }^{4}$ Nos municípios marcados com * está instalado o Corpo de Bombeiros Voluntários (ABVESC, 2018).

${ }^{5}$ Nos municípios de Balneário Barra do Sul e Penha há quartel do CBMSC destinados somente ao SAT.

${ }^{6}$ Informações referentes aos municípios que não aparecem nas tabelas acima podem ser verificadas através do seguinte link: $<$ https://docs.google.com/spreadsheets/d/1f12FWnl3BkVkflQa9M9q2OlxDH4XyHAw1dhm7Z9-

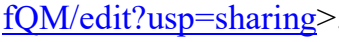


Revista Científica do Corpo de Bombeiros Militar de Pernambuco

XVIII Seminário Nacional de Bombeiros - Foz do Iguaçu PR

Vol.04 No11 - Edição Especial XVIII SENABOM - ISSN 2359-4829

Versão on-line disponível em: http://www.revistaflammae.com.

100.000 habitantes foi de 2,69. Índice bem próximo à média do Estado, que ficou em 2,56. Quanto ao seu número de óbitos absoluto, a capital apresenta o maior número de óbitos dentre os demais 294 municípios, apresentando uma média de 13 casos por ano. Em Florianópolis há 5 quartéis operacionais do CBMSC.

Tabela 5: Índice relativo de óbitos por afogamento do $1^{\circ} \mathrm{BBM}^{7}$.

\begin{tabular}{|c|c|c|c|c|}
\hline $\begin{array}{c}\text { Classific } \\
\text { ação }\end{array}$ & Município & $\begin{array}{c}\text { Possui } \\
\text { OBM }\end{array}$ & $\begin{array}{c}\text { Número absoluto de óbitos por } \\
\text { afogamento de 10 de janeiro de 1989 a } \\
\text { 31 de dezembro de 2015 }\end{array}$ & $\begin{array}{c}\text { Índice relativo de óbitos por } \\
\text { afogamento a cada 100.000 } \\
\text { habitantes por ano no período }\end{array}$ \\
\hline $1^{\circ}$ & Florianópolis & Sim & 353 & 2,69 \\
\hline
\end{tabular}

Fonte: Do autor.

Para o $2^{\circ}$ BBM, sediado em Curitibanos, composto por 24 municípios localizados no planalto serrano e meio-oeste do Estado, foram obtidos os seguintes resultados para os 10 (dentre 24) municípios com os maiores índices:

Tabela 6: Classificação, em ordem decrescente, dos 10 municípios com os maiores índices relativos de óbitos por afogamento do $2^{\circ}$ BBM.

\begin{tabular}{|c|c|c|c|c|}
\hline Classificação & Município & $\begin{array}{c}\text { Possui } \\
\text { OBM }\end{array}$ & $\begin{array}{c}\text { Número absoluto de óbitos por } \\
\text { afogamento de 1 de janeiro de } \\
\text { 1989 a 31 de dezembro de 2015 }\end{array}$ & $\begin{array}{c}\text { Índice relativo de óbitos por } \\
\text { afogamento a cada 100.000 } \\
\text { habitantes por ano no período }\end{array}$ \\
\hline $1^{\circ}$ & Tangará & Sim & 15 & 6,36 \\
\hline $2^{\circ}$ & Vargem & Não & 3 & 4,37 \\
\hline $3^{\circ}$ & Abdon Batista & Não & 3 & 4,27 \\
\hline $4^{\circ}$ & Caçador* & Sim - SAT & 82 & 3,93 \\
\hline $5^{\circ}$ & Lebon Régis & Sim & 11 & 3,36 \\
\hline $6^{\circ}$ & Timbó Grande & Não & 7 & 3,34 \\
\hline $7^{\circ}$ & Santa Cecília & Sim & 15 & 3,33 \\
\hline $8^{\circ}$ & Campos & Sim & 30 & 3,11 \\
\hline $9^{\circ}$ & Celso Ramos & Não & 2 & 2,68 \\
\hline $10^{\circ}$ & Videira & Sim & 34 & 2,42 \\
\hline
\end{tabular}

Fonte: Do autor.

\footnotetext{
${ }^{7} \mathrm{O} 1^{\circ} \mathrm{BBM}$ é integrado por um único município, qual seja, Florianópolis.
} 


\section{Revista FLAMMAE}

Revista Científica do Corpo de Bombeiros Militar de Pernambuco

XVIII Seminário Nacional de Bombeiros - Foz do Iguaçu PR

Vol.04 No11 - Edição Especial XVIII SENABOM - ISSN 2359-4829

Versão on-line disponível em: http://www.revistaflammae.com.

No $2^{\circ} \mathrm{BBM}$, o município de Tangará lidera a lista sendo o único com índice igual ou superior a 5 .

Destaca-se também, para além do índice relativo, os números absolutos inerentes às mortes por afogamento no período aqui estudado, números estes que dão destaques diferentes ao municípios, conforme os percentuais apresentados no gráfico a seguir:

Gráfico 1: Números absolutos de óbitos por afogamento no $2^{\circ} \mathrm{BBM}$ de 1989 a 2015.

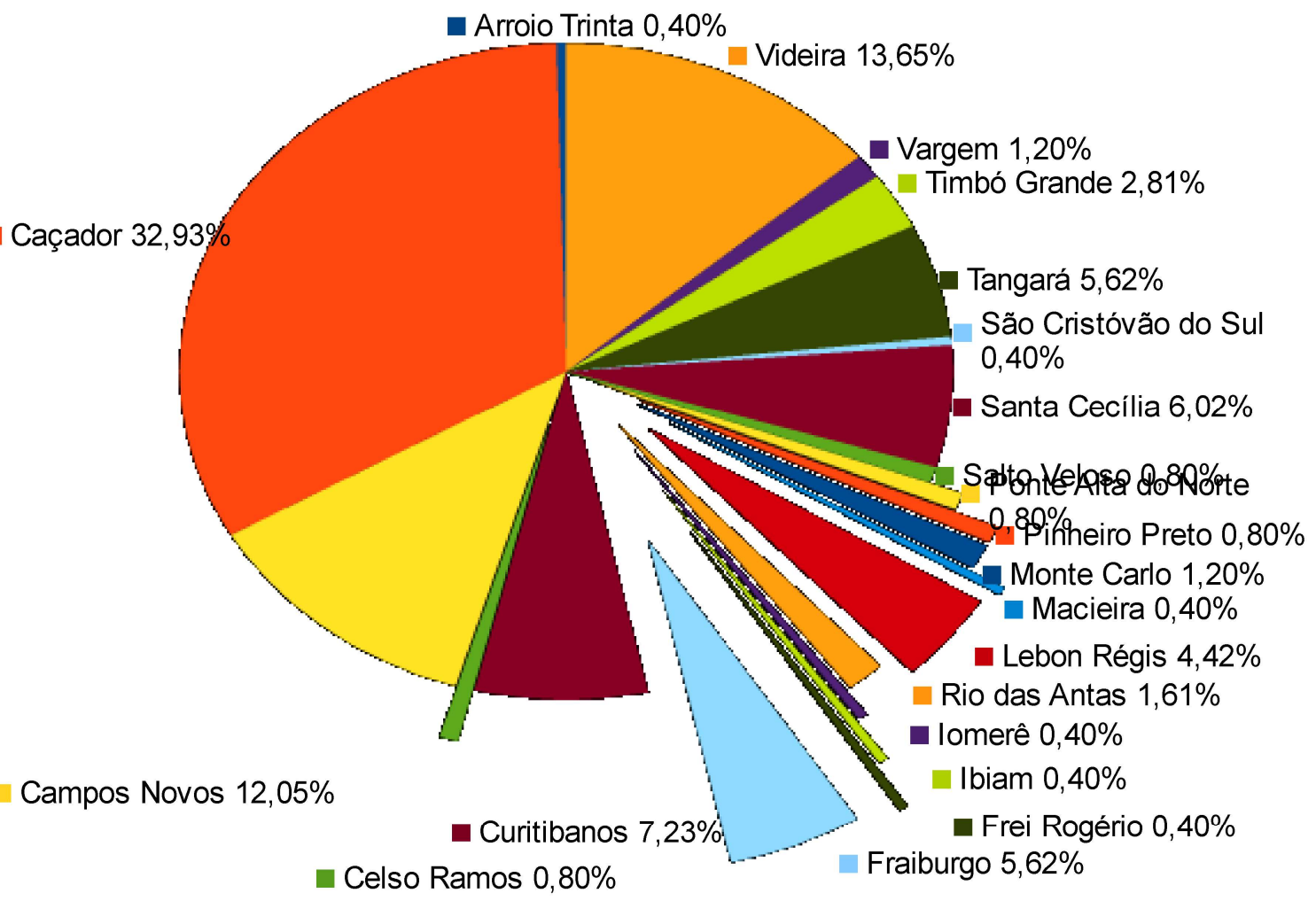

- Arroio Trinta
Caçador
Campos Novos
Celso Ramos
- Curitibanos
Fraiburgo
Frei Rogério
Ibiam
- lomerê
Rio das Antas
Lebon Régis
Macieira
Monte Carlo
Pinheiro Preto
Ponte Alta do Nor-
te
Salto Veloso
Santa Cecília
São Cristóvão do
Sul
Tangará
Timbó Grande
Vargem
Videira

Fonte: Do autor.

Dos 252 óbitos ocorridos na área do $2^{\circ} \mathrm{BBM}$, de 4.831 ocorridos em todo o Estado de SC, mais de 30\% ocorreram no município de Caçador (82 casos). Destacamse também, em números absolutos, os municípios de Videira com 34 casos (13,65\%) e 
Revista Científica do Corpo de Bombeiros Militar de Pernambuco

XVIII Seminário Nacional de Bombeiros - Foz do Iguaçu PR

Vol.04 No11 - Edição Especial XVIII SENABOM - ISSN 2359-4829

Versão on-line disponível em: http://www.revistaflammae.com.

Campos Novos com 30 óbitos por afogamento (12,05\%). Para os casos do $2^{\circ} \mathrm{BBM}$, destaca-se que, dentre os dez municípios à cima listados, em cinco deles o CBMSC atua com o serviço operacional ${ }^{8}$, quais sejam, Tangará, Lebon Régis, Santa Cecília, Campos Novos e Videira.

Dando continuidade, quanto ao $3^{\circ} \mathrm{BBM}$, sediado em Blumenau, formado por 14 municípios, apresenta-se na tabela a seguir os 10 com os maiores índices relativos de óbitos por afogamento no período estudado:

Tabela 7: Classificação, em ordem decrescente, dos 10 municípios com os maiores índices relativos de óbitos por afogamento do $3^{\circ} \mathrm{BBM}$.

\begin{tabular}{|c|c|c|c|c|}
\hline Classificação & Município & $\begin{array}{c}\text { Possui } \\
\text { OBM }\end{array}$ & $\begin{array}{c}\text { Número absoluto de óbitos por } \\
\text { afogamento de 1 } \\
\text { 1989 a 31 de dezembro de 2015 }\end{array}$ & $\begin{array}{c}\text { Índice relativo de óbitos por } \\
\text { afogamento a cada 100.000 } \\
\text { habitantes por ano no período }\end{array}$ \\
\hline $1^{\circ}$ & Ascurra* & Não & 13 & 6,11 \\
\hline $2^{\circ}$ & Rio dos Cedros & Sim & 15 & 4,86 \\
\hline $3^{\circ}$ & Apiúna* & Sim & 10 & 3,51 \\
\hline $4^{\circ}$ & Botuverá & Sim & 4 & 2,90 \\
\hline $5^{\circ}$ & Doutor Pedrinho & Não & 3 & 2,75 \\
\hline $6^{\circ}$ & Benedito Novo & Sim & 7 & 2,27 \\
\hline $7^{\circ}$ & Rodeio* & Não & 7 & 2,26 \\
\hline $8^{\circ}$ & Timbó & Sim & 21 & 1,82 \\
\hline $9^{\circ}$ & Gaspar & Sim & 27 & 1,48 \\
\hline $10^{\circ}$ & Indaial* & Sim & 26 & 1,45 \\
\hline
\end{tabular}

Fonte: Do autor.

$\mathrm{Na}$ área deste $\mathrm{BBM}$, o único município com índice igual ou superior a 5 é Ascurra. Gaspar é o município listado com o maior número absoluto de casos (27). Apesar de Blumenau não aparecer na lista à cima ( $11^{\circ}$ da lista $)$ em virtude de sua grande população, este município é o que apresenta o maior número absoluto de óbitos por afogamento na área do $3^{\circ} \mathrm{BBM}$ no período estudado, com 91 óbitos. $\mathrm{Na}$ área do $3^{\circ}$ BBM, só não há OBM em Ascurra, Doutor Pedrinho e Rodeio.

Ao analisar-se os resultados obtidos para os 25 municípios do BBM seguinte, o $4^{\circ} \mathrm{BBM}$, sediado em Criciúma, observa-se uma grande diferença quanto aos demais até

$8 \quad$ No município de Caçador, a OBM é destinada somente ao SAT. 
Revista Científica do Corpo de Bombeiros Militar de Pernambuco

XVIII Seminário Nacional de Bombeiros - Foz do Iguaçu PR

Vol.04 No11 - Edição Especial XVIII SENABOM - ISSN 2359-4829

Versão on-line disponível em: http://www.revistaflammae.com.

aqui apresentados, haja vista que os dez municípios listados apresentam índices igual ou superiores a 5 :

Tabela 8: Classificação, em ordem decrescente, dos 10 municípios com os maiores índices relativos de óbitos por afogamento do $4^{\circ} \mathrm{BBM}$.

\begin{tabular}{|c|c|c|c|c|}
\hline Classificação & Município & $\begin{array}{c}\text { Possui } \\
\text { OBM }\end{array}$ & $\begin{array}{c}\text { Número absoluto de óbitos por } \\
\text { afogamento de 1 de janeiro de } \\
\mathbf{1 9 8 9} \text { a 31 de dezembro de 2015 }\end{array}$ & $\begin{array}{c}\text { Índice relativo de óbitos por } \\
\text { afogamento a cada 100.000 } \\
\text { habitantes por ano no período }\end{array}$ \\
\hline $1^{\circ}$ & Passo de Torres & Sim & 34 & 15,04 \\
\hline $2^{\circ}$ & Timbé do Sul & Não & 11 & 7,58 \\
\hline $3^{\circ}$ & $\begin{array}{c}\text { Balneário Arroio } \\
\text { do Silva }\end{array}$ & Sim & 24 & 7,2 \\
\hline $4^{\circ}$ & Treviso & Não & 7 & 6,71 \\
\hline $5^{\circ}$ & Nova Veneza & Não & 26 & 6,49 \\
\hline $6^{\circ}$ & Meleiro & Não & 12 & 6,31 \\
\hline $7^{\circ}$ & Ermo & Não & 3 & 5,35 \\
\hline $8^{\circ}$ & Morro Grande & Não & 4 & 5,08 \\
\hline $9^{\circ}$ & Balneário & Sim & 17 & 5,08 \\
\hline $1^{\circ}$ & Rincão & & & 10 \\
\hline
\end{tabular}

Fonte: Do autor.

Quanto ao número absoluto de óbitos, destaque, na tabela, para os municípios de Passo de Torres (34 casos) e, para além da tabela, Içara (não-litorâneo), com 50 casos (11 $1^{\circ}$ lugar - índice relativo de 3,38) e Araranguá, com 56 casos (12 lugar - índice relativo de 3,09), ambas cidades aonde o CBMSC está presente. Há OBM em três dos 10 municípios da Tabela 8: Passo de Torres, Balneário Arroio do Silva e Balneário Rincão. Dentre estes dez, três estão às margens do litoral.

Para o BBM seguinte, $5^{\circ} \mathrm{BBM}$, sediado em Lages, integrado até a presente data por 48 municípios localizados, predominantemente, na região serrana de Santa Catarina, têm-se os nove primeiros municípios da lista com índices iguais ou superiores a 5 . $\mathrm{Na}$ área deste BBM, o município destaque quanto ao número absoluto de óbitos por afogamento é Lages, ocupando a $7^{\mathrm{a}}$ colocação em todo o estado, com $129 \operatorname{casos}\left(21^{\mathrm{o}}\right.$ lugar - índice relativo de 3,01). Dentre os dez municípios do $5^{\circ} \mathrm{BBM}$ listados, há Organização de Bombeiro Militar (OBM) somente em Correia Pinto. 


\section{Revista FLAMMAE}

Revista Científica do Corpo de Bombeiros Militar de Pernambuco

XVIII Seminário Nacional de Bombeiros - Foz do Iguaçu PR

Vol.04 No11 - Edição Especial XVIII SENABOM - ISSN 2359-4829

Versão on-line disponível em: http://www.revistaflammae.com.

Tabela 9: Classificação, em ordem decrescente, dos 10 municípios com os maiores índices relativos de óbitos por afogamento do $5^{\circ} \mathrm{BBM}$.

\begin{tabular}{|c|c|c|c|c|}
\hline Classificação & Município & $\begin{array}{c}\text { Possui } \\
\text { OBM }\end{array}$ & $\begin{array}{c}\text { Número absoluto de óbitos por } \\
\text { afogamento de 10 de janeiro de } \\
\mathbf{1 9 8 9} \text { a 31 de dezembro de 2015 }\end{array}$ & $\begin{array}{c}\text { Índice relativo de óbitos por } \\
\text { afogamento a cada 100.000 } \\
\text { habitantes por ano no período }\end{array}$ \\
\hline $1^{\circ}$ & Palmeira & Não & 6 & 8,59 \\
\hline $2^{\circ}$ & Santa Terezinha & Não & 20 & 8,37 \\
\hline $3^{\circ}$ & José Boiteux & Não & 9 & 6,82 \\
\hline $4^{\circ}$ & Presidente Nereu & Não & 4 & 6,43 \\
\hline $5^{\circ}$ & Ponte Alta & Não & 8 & 6,22 \\
\hline $6^{\circ}$ & Rio do Campo & Não & 10 & 6,13 \\
\hline $7^{\circ}$ & Lontras* & Não & 17 & 5,35 \\
\hline $8^{\circ}$ & Correia Pinto & Sim & 10 & 5,27 \\
\hline $9^{\circ}$ & Campo Belo do Sul $*$ & Não & 5 & 5,16 \\
\hline $10^{\circ}$ & Braço do Trombudo & Não & 4,99 \\
\hline
\end{tabular}

Fonte: Do autor.

$\mathrm{Na}$ sequência, localizados na região oeste catarinense, estão 10 dos 28 municípios que integram o $6^{\circ} \mathrm{BBM}$, sediado em Chapecó, com os maiores índices deste BBM, dentre os quais 7 apresentaram número igual ou superior a 5. Dentre eles, há OBM operacional apenas em Saudades ${ }^{9}$.

Tabela 10: Classificação, em ordem decrescente, dos 10 municípios com os maiores índices relativos de óbitos por afogamento do $6^{\circ} \mathrm{BBM}$.

\begin{tabular}{|c|c|c|c|c|}
\hline Classificação & Município & $\begin{array}{c}\text { Possui } \\
\text { OBM }\end{array}$ & $\begin{array}{l}\text { Número absoluto de óbitos por } \\
\text { afogamento de } 1^{\circ} \text { de janeiro de } \\
1989 \text { a } 31 \text { de dezembro de } 2015\end{array}$ & $\begin{array}{l}\text { Índice relativo de óbitos por } \\
\text { afogamento a cada } 100.000 \\
\text { habitantes por ano no período }\end{array}$ \\
\hline $1^{\circ}$ & Paial & Não & 4 & 9,39 \\
\hline $2^{\circ}$ & Águas Frias & Não & 6 & 9,31 \\
\hline $3^{\circ}$ & Arvoredo & Não & 5 & 8,19 \\
\hline $4^{\circ}$ & Guatambú & Não & 9 & 7,04 \\
\hline $5^{\circ}$ & Nova Erechim & Não & 8 & 6,07 \\
\hline $6^{\circ}$ & Caxambu do Sul & Não & 6 & 5,77 \\
\hline $7^{\circ}$ & Nova Itaberaba & Não & 6 & 5,12 \\
\hline $8^{\circ}$ & Concórdia* & Sim - SAT & 89 & 4,47 \\
\hline $9^{\circ}$ & Itá & Sim - SAT & 7 & 4,13 \\
\hline $10^{\circ}$ & Saudades & Sim & 8 & 3,07 \\
\hline
\end{tabular}

Fonte: Do autor.

\footnotetext{
${ }^{9}$ Nos municípios de Concórdia e Itá a OBM é destinada somente ao SAT.
} 
Revista Científica do Corpo de Bombeiros Militar de Pernambuco XVIII Seminário Nacional de Bombeiros - Foz do Iguaçu PR

Vol.04 No11 - Edição Especial XVIII SENABOM - ISSN 2359-4829

Versão on-line disponível em: http://www.revistaflammae.com.

Para este BBM, os destaques inerentes aos números absolutos são dados aos municípios de Concórdia, e Chapecó, sendo este com 81 casos (16º lugar - índice relativo de 1,41).

Voltando-se à região litorânea, tem-se o $7^{\circ} \mathrm{BBM}$, sediado em Itajaí, integrado por 19 municípios da região norte de SC, dentre os quais 10 estão listados a seguir:

Tabela 11: Classificação, em ordem decrescente, dos 10 municípios com os maiores índices relativos de óbitos por afogamento do $7^{\circ} \mathrm{BBM}$.

\begin{tabular}{|c|c|c|c|c|}
\hline Classificação & Município & $\begin{array}{c}\text { Possui } \\
\text { OBM }\end{array}$ & $\begin{array}{c}\text { Número absoluto de óbitos por } \\
\text { afogamento de 1 de janeiro de } \\
\mathbf{1 9 8 9} \text { a 31 de dezembro de 2015 }\end{array}$ & $\begin{array}{c}\text { Índice relativo de óbitos por } \\
\text { afogamento a cada 100.000 } \\
\text { habitantes por ano no período }\end{array}$ \\
\hline $1^{\circ}$ & Itapoá & Sim & 91 & 17,41 \\
\hline $2^{\circ}$ & $\begin{array}{c}\text { Balneário Barra do } \\
\text { Sul* }\end{array}$ & Sim - SAT & 47 & 16,87 \\
\hline $3^{\circ}$ & $\begin{array}{c}\text { São Francisco do } \\
\text { Sul* }\end{array}$ & Sim & 166 & 12,13 \\
\hline $4^{\circ}$ & Barra Velha* & Sim & 85 & 11,33 \\
\hline $5^{\circ}$ & Penha* & Sim - SAT & 85 & 10,15 \\
\hline $6^{\circ}$ & Garuva & Sim & 44 & 9,32 \\
\hline $7^{\circ}$ & Navegantes* & Sim & 152 & 7,30 \\
\hline $8^{\circ}$ & Balneário Piçarras & Sim & 43 & 7,28 \\
\hline $9^{\circ}$ & Itajaí & Sim & 293 & 5,10 \\
\hline $1^{\circ}$ & São João do & Não & 4 & 4,01 \\
\hline
\end{tabular}

Fonte: Do autor.

Semelhante à tabela que representa os municípios do litoral sul, 9 dos 10 municípios com os maiores índices do $7^{\circ} \mathrm{BBM}$ apresentam números iguais ou superiores a 5. Todos os 9, inclusive, apresentando número absoluto de óbitos que representam mais de um caso por ano durante o período estudado. Note-se que, dentre este 9, apenas Garuva não encontra-se na região litorânea e, em todos os nove, há $\mathrm{OBM}^{10}$. Ainda na área do $7^{\circ} \mathrm{BBM}$, destacam-se com relação aos números absolutos, os municípios de Guaramirim com 33 casos ( $12^{\circ}$ lugar - índice relativo de 2,85), Joinville, com 183 casos $\left(17^{\circ}\right.$ lugar - índice relativo de 1,17$)$, o qual figura como a $4^{\text {a }}$ cidade do

\footnotetext{
${ }^{10}$ Nos municípios de Balneário Barra do Sul e Penha, a OBM é destinada somente ao SAT.
} 
Revista Científica do Corpo de Bombeiros Militar de Pernambuco

XVIII Seminário Nacional de Bombeiros - Foz do Iguaçu PR

Vol.04 No11 - Edição Especial XVIII SENABOM - ISSN 2359-4829

Versão on-line disponível em: http://www.revistaflammae.com.

Estado em números absolutos de óbito por afogamento e Jaraguá do Sul, com 32 casos $\left(19^{\circ} \text { lugar - índice relativo de } 0,69\right)^{11}$.

Voltando para o litoral sul do Estado, está o $8^{\circ} \mathrm{BBM}$, sediado no município de Tubarão e composto por 21 municípios, dentre os quais, apresenta-se à seguir os $10 \mathrm{com}$ os maiores índices relativos de óbitos por afogamento sendo que 6 apresentam índice igual ou superior a 5 .

Tabela 12: Classificação, em ordem decrescente, dos 10 municípios com os maiores índices relativos de óbitos por afogamento do $8^{\circ} \mathrm{BBM}$.

\begin{tabular}{|c|c|c|c|c|}
\hline Classificação & Município & $\begin{array}{c}\text { Possui } \\
\text { OBM }\end{array}$ & $\begin{array}{c}\text { Número absoluto de óbitos por } \\
\text { afogamento de 1 de janeiro de } \\
\text { 1989 a 31 de dezembro de 2015 }\end{array}$ & $\begin{array}{c}\text { Índice relativo de óbitos por } \\
\text { afogamento a cada 100.000 } \\
\text { habitantes por ano no período }\end{array}$ \\
\hline $1^{\circ}$ & Jaguaruna* & Sim-SAT & 44 & 8,35 \\
\hline $2^{\circ}$ & Laguna & Sim & 93 & 7,60 \\
\hline $3^{\circ}$ & Santa Rosa de Lima & Não & 4 & 6,93 \\
\hline $4^{\circ}$ & São Martinho & Não & 6 & 6,92 \\
\hline $5^{\circ}$ & Rio Fortuna & Não & 7 & 5,63 \\
\hline $6^{\circ}$ & Garopaba & Sim & 31 & 5,20 \\
\hline $7^{\circ}$ & Imaruí & Não & 14 & 4,91 \\
\hline $8^{\circ}$ & Pedras Grandes & Não & 4 & 3,68 \\
\hline $9^{\circ}$ & Grão Pará & Não & 6 & 3,40 \\
\hline $10^{\circ}$ & Orleans & Sim & 17 & 2,77 \\
\hline
\end{tabular}

Fonte: Do autor.

Note-se, nos casos supracitados, os elevados índices absolutos do municípios de Jaguaruna, Laguna e Garopaba. Além destes, quanto aos índices absolutos, destacam-se também Imbituba com 31 casos $\left(12^{\circ}\right.$ lugar - índice relativo de 2,60), e Tubarão, com 56 casos $\left(15^{\circ}\right.$ lugar - índice relativo de 1,99$)$.

Para a área do $9^{\circ} \mathrm{BBM}$, sediada em Canoinhas e integrada por 15 cidades, foi obtido índice igual ou superior a 5 para 1 município; entre 4,99 e 4 para 2 municípios; de 2,99 a 2 para 3 municípios e; igual ou inferior a 1,99 para os 3 últimos da tabela dos 10 .

11 Nos municípios de Guaramirim, Joinville e Jaraguá do Sul, a OBM é destinada ao Serviço de Atividades Técnicas (SAT). 
Revista Científica do Corpo de Bombeiros Militar de Pernambuco

XVIII Seminário Nacional de Bombeiros - Foz do Iguaçu PR

Vol.04 No11 - Edição Especial XVIII SENABOM - ISSN 2359-4829

Versão on-line disponível em: http://www.revistaflammae.com.

Tabela 13: Classificação, em ordem decrescente, dos 10 municípios com os maiores índices relativos de óbitos por afogamento do $9^{\circ} \mathrm{BBM}$.

\begin{tabular}{|c|c|c|c|c|}
\hline Classificação & Município & $\begin{array}{c}\text { Possui } \\
\text { OBM }\end{array}$ & $\begin{array}{c}\text { Número absoluto de óbitos por } \\
\text { afogamento de 1 } \\
\text { 1989 a 31 de dezembro de 2015 }\end{array}$ & $\begin{array}{c}\text { Índice relativo de óbitos por } \\
\text { afogamento a cada 100.000 } \\
\text { habitantes por ano no período }\end{array}$ \\
\hline $1^{\circ}$ & Itaiópolis* & Não & 32 & 5,51 \\
\hline $2^{\circ}$ & Calmon & Não & 4 & 4,38 \\
\hline $3^{\circ}$ & Mafra & Sim & 66 & 4,37 \\
\hline $4^{\circ}$ & Irineópolis & Não & 10 & 3,33 \\
\hline $5^{\circ}$ & Bela Vista do Toldo & Não & 5 & 2,94 \\
\hline $6^{\circ}$ & Porto União & Sim & 25 & 2,63 \\
\hline $7^{\circ}$ & Três Barras & Sim & 12 & 2,32 \\
\hline $8^{\circ}$ & Rio Negrinho & Não & 17 & 1,50 \\
\hline $9^{\circ}$ & Matos Costa & Sim & 1 & 1,42 \\
\hline $10^{\circ}$ & Papanduva & Sim & 5 & 0,97 \\
\hline
\end{tabular}

Fonte: Do autor.

Dos 10 municípios supracitados, há OBM em Mafra, Porto União, Três Barras, Matos Costa e Papanduva. Em Itaiópolis, não há OBM, mas verifica-se alto índice relativo e absoluto para o caso estudado.

Chama a atenção nos dados analisados, o número de óbitos registrados (e provavelmente atendidos pelo CBMSC) em municípios do Estado do Paraná. Em 10 municípios $^{12}$ paranaenses foram registrados 108 óbitos enquanto na área do $9^{\circ} \mathrm{BBM}$ foram registrados 212 casos.

Por sua vez, na região da Grande Florianópolis, com exceção da capital, 13 municípios compõe o $10^{\circ} \mathrm{BBM}$, sediado na cidade de São José. Dentre eles, apresentase a seguir, o índice das 10 cidades mais vulneráveis aos óbitos por afogamento do BBM, sendo que apenas 3 apresentaram índice igual ou superior a 5. Para o BBM de São José, o destaque para além da tabela fica por conta do município-sede, o qual apresentou um número absoluto de 55 casos no período em questão. No $10^{\circ} \mathrm{BBM}$ não há OOBBMM nos municípios de São Bonifácio, Anitápolis, Águas Mornas e Angelina ${ }^{13}$.

\footnotetext{
${ }^{12}$ Bituruna, Cruz Machado, General Carneiro, Mallet, Paula Freitas, Paula Frontin, Piên, Porto Vitórias, Rio Negro e União da Vitória.

${ }^{13}$ Nos municípios de Antônio Carlos e Paulo Lopes a OBM é destinada somente ao SAT.
} 


\section{Revista FLAMMAE}

Revista Científica do Corpo de Bombeiros Militar de Pernambuco

XVIII Seminário Nacional de Bombeiros - Foz do Iguaçu PR

Vol.04 No11 - Edição Especial XVIII SENABOM - ISSN 2359-4829

Versão on-line disponível em: http://www.revistaflammae.com.

Tabela 14: Classificação, em ordem decrescente, dos 10 municípios com os maiores índices relativos de óbitos por afogamento do $10^{\circ} \mathrm{BBM}$.

\begin{tabular}{|c|c|c|c|c|}
\hline Classificação & Município & $\begin{array}{c}\text { Possui } \\
\text { OBM }\end{array}$ & $\begin{array}{c}\text { Número absoluto de óbitos por } \\
\text { afogamento de 1 de janeiro de } \\
\mathbf{1 9 8 9} \text { a 31 de dezembro de 2015 }\end{array}$ & $\begin{array}{c}\text { Índice relativo de óbitos por } \\
\text { afogamento a cada 100.000 } \\
\text { habitantes por ano no período }\end{array}$ \\
\hline $1^{\circ}$ & $\begin{array}{c}\text { Governador Celso } \\
\text { Ramos }\end{array}$ & Sim & 27 & 7,03 \\
\hline $2^{\circ}$ & São Bonifácio & Não & 5 & 6,39 \\
\hline $3^{\circ}$ & Anitápolis & Não & 5 & 5,70 \\
\hline $4^{\circ}$ & Águas Mornas & Não & 5 & 2,94 \\
\hline $5^{\circ}$ & $\begin{array}{c}\text { Santo Amaro da } \\
\text { Imperatriz }\end{array}$ & Sim & 17 & 2,78 \\
\hline $6^{\circ}$ & Antônio Carlos & Sim-SAT & 6 & 2,67 \\
\hline $7^{\circ}$ & Paulo Lopes & Sim-SAT & 5 & 2,52 \\
\hline $8^{\circ}$ & Palhoça & Sim & 104 & 2,34 \\
\hline $9^{\circ}$ & Angelina & Não & 3 & 2,25 \\
\hline $10^{\circ}$ & Biguaçu & Sim & 35 & 1,95 \\
\hline
\end{tabular}

Fonte: Do autor.

Tratando-se do $11^{\circ} \mathrm{BBM}$, sediado em Joaçaba e composto por 19 cidades, têmse 3 municípios com índices iguais ou superiores a 5:

Tabela 15: Classificação, em ordem decrescente, dos 10 municípios com os maiores índices relativos de óbitos por afogamento do $11^{\circ} \mathrm{BBM}$.

\begin{tabular}{|c|c|c|c|c|}
\hline Classificação & Município & $\begin{array}{c}\text { Possui } \\
\text { OBM }\end{array}$ & $\begin{array}{c}\text { Número absoluto de óbitos por } \\
\text { afogamento de 1 de janeiro de } \\
\mathbf{1 9 8 9} \text { a 31 de dezembro de 2015 }\end{array}$ & $\begin{array}{c}\text { Índice relativo de óbitos por } \\
\text { afogamento a cada 100.000 } \\
\text { habitantes por ano no período }\end{array}$ \\
\hline $1^{\circ}$ & Lacerdópolis & Não & 5 & 8,23 \\
\hline $2^{\circ}$ & Piratuba & Sim & 7 & 6,32 \\
\hline $3^{\circ}$ & Erval Velho & Não & 2 & 5,79 \\
\hline $4^{\circ}$ & Presidente Castello & Não & 4 & 4,60 \\
\hline $5^{\circ}$ & Ibicaré & Não & 27 & 4,53 \\
\hline $6^{\circ}$ & Herval d Oeste & Sim & 6 & 4,46 \\
\hline $7^{\circ}$ & Luzerna & Não & 2 & 3,90 \\
\hline $8^{\circ}$ & Alto Bela Vista & Não & 4 & 3,77 \\
\hline $9^{\circ}$ & Ipira & Não & 4 & 3,25 \\
\hline $10^{\circ}$ & Vargem Bonita & Não & 4,22 \\
\hline
\end{tabular}

Fonte: Do autor. 
Revista Científica do Corpo de Bombeiros Militar de Pernambuco

XVIII Seminário Nacional de Bombeiros - Foz do Iguaçu PR

Vol.04 No11 - Edição Especial XVIII SENABOM - ISSN 2359-4829

Versão on-line disponível em: http://www.revistaflammae.com.

Nesta condição, dá-se destaque ao município de Herval d'Oeste no que diz respeito ao número absoluto de óbitos por afogamento, atingindo um caso por ano. No BBM de Joaçaba, dentre os municípios listados à cima, há OBM em: Piratuba e em Herval d'Oeste.

Seguindo para o extremo oeste de SC, tem-se o $12^{\circ} \mathrm{BBM}$, sediado em São Miguel do Oeste e composto por 28 cidades. Dentre elas, na lista dos 10 municípios com os maiores índices, apenas um apresenta-se com índice igual ou superior a 5, o município de Flor do Sertão. Quanto aos números absolutos, a situação mais vulnerável é apresentada pelo município de Palma Sola, o único dentre os 10 listados aonde há OBM, aonde verificou-se uma média de um óbito por afogamento a cada 4,5 anos.

Tabela 16: Classificação, em ordem decrescente, dos 10 municípios com os maiores índices relativos de óbitos por afogamento do $12^{\circ} \mathrm{BBM}$.

\begin{tabular}{|c|c|c|c|c|}
\hline Classificação & Município & $\begin{array}{c}\text { Possui } \\
\text { OBM }\end{array}$ & $\begin{array}{c}\text { Número absoluto de óbitos por } \\
\text { afogamento de 1 } \\
\text { de1989 a 31 de dezembro de 2015 }\end{array}$ & $\begin{array}{c}\text { Índice relativo de óbitos por } \\
\text { afogamento a cada 100.000 } \\
\text { habitantes por ano no período }\end{array}$ \\
\hline $1^{\circ}$ & Flor do Sertão & Não & 3 & 6,97 \\
\hline $2^{\circ}$ & Iraceminha & Não & 5 & 4,55 \\
\hline $3^{\circ}$ & Belmonte & Não & 3 & 4,10 \\
\hline $4^{\circ}$ & Riqueza & Não & 5 & 3,97 \\
\hline $5^{\circ}$ & Santa Helena & Não & 2 & 3,27 \\
\hline $6^{\circ}$ & Tunápolis & Não & 4 & 3,22 \\
\hline $7^{\circ}$ & Palma Sola & Sim & 6 & 2,94 \\
\hline $8^{\circ}$ & Anchieta & Não & 4 & 2,54 \\
\hline $9^{\circ}$ & Guarujá do Sul & Não & 3 & 2,16 \\
\hline $1^{\circ}$ & Barra Bonita & Não & 1 & 2,13 \\
\hline
\end{tabular}

Fonte: Do autor.

De volta à região do litoral centro-norte de $\mathrm{SC}$, sediado em Balneário Camboriú e composto por 10 municípios, todos aparecendo na lista à baixo, está o $13^{\circ} \mathrm{BBM}$. Dentre os 10, três apresentam índices iguais ou superiores a 5 . O número absoluto de óbitos por afogamento nos municípios do $13^{\circ}$ é superior a 27 , para o período estudado, em Bombinhas, Porto Belo, Balneário Camboriú, Itapema e Tijucas. Em todas estas cidades, há OBM. 
Revista Científica do Corpo de Bombeiros Militar de Pernambuco

XVIII Seminário Nacional de Bombeiros - Foz do Iguaçu PR

Vol.04 No11 - Edição Especial XVIII SENABOM - ISSN 2359-4829

Versão on-line disponível em: http://www.revistaflammae.com.

Tabela 17: Classificação, em ordem decrescente, dos 10 municípios com os maiores índices relativos de óbitos por afogamento do $13^{\circ} \mathrm{BBM}$.

\begin{tabular}{|c|c|c|c|c|}
\hline Classificação & Município & $\begin{array}{l}\text { Possui } \\
\text { OBM }\end{array}$ & $\begin{array}{l}\text { Número absoluto de óbitos por } \\
\text { afogamento de } 1^{\circ} \text { de janeiro } \\
\text { de1989 a } 31 \text { de dezembro de } 2015\end{array}$ & $\begin{array}{c}\text { Índice relativo de óbitos por } \\
\text { afogamento a cada } 100.000 \\
\text { habitantes por ano no período }\end{array}$ \\
\hline $1^{\circ}$ & Bombinhas & Sim & 51 & 10,14 \\
\hline $2^{\circ}$ & Porto Belo & Sim & 45 & 8,21 \\
\hline $3^{\circ}$ & $\begin{array}{l}\text { Balneário } \\
\text { Camboriú }\end{array}$ & Sim & 191 & 5,23 \\
\hline $4^{\circ}$ & Itapema & Sim & 78 & 4,72 \\
\hline $5^{\circ}$ & Tijucas & Sim & 29 & 2,91 \\
\hline $6^{\circ}$ & Canelinha & Sim & 6 & 1,86 \\
\hline $7^{\circ}$ & Camboriú & Sim & 24 & 1,13 \\
\hline $8^{\circ}$ & São João Batista & Sim & 5 & 0,53 \\
\hline $9^{\circ}$ & Nova Trento & Sim & 1 & 0,26 \\
\hline $10^{\circ}$ & Major Gercino & Sim & 0 & 0 \\
\hline
\end{tabular}

Fonte: Do autor.

Finalizando, tem-se o mais novo BBM, o $14^{\circ}$, sediado em Xanxerê e integrado por 30 municípios, dentre os quais, 10 aparecem listados a seguir, sendo 3 com índices igual ou superior a 5. Dentre os 10 listados, há OBM em: São Domingos, Campo Erê e São Lourenço do Oeste.

Tabela 18: Classificação, em ordem decrescente, dos 10 municípios com os maiores índices relativos de óbitos por afogamento do $14^{\circ} \mathrm{BBM}$.

\begin{tabular}{|c|c|c|c|c|}
\hline Classificação & Município & $\begin{array}{c}\text { Possui } \\
\text { OBM }\end{array}$ & $\begin{array}{l}\text { Número absoluto de óbitos por } \\
\text { afogamento de } 1^{\circ} \text { de janeiro } \\
\text { de1989 a } 31 \text { de dezembro de } 2015\end{array}$ & $\begin{array}{l}\text { Índice relativo de óbitos por } \\
\text { afogamento a cada } 100.000 \\
\text { habitantes por ano no período }\end{array}$ \\
\hline $1^{\circ}$ & Marema & Não & 5 & 9,72 \\
\hline $2^{\circ}$ & Jardinópolis & Não & 4 & 9,12 \\
\hline $3^{\circ}$ & Santiago do Sul & Não & 2 & 5,62 \\
\hline $4^{\circ}$ & Ouro Verde & Não & 3 & 4,95 \\
\hline $5^{\circ}$ & Passos Maia & Não & 5 & 4,36 \\
\hline $6^{\circ}$ & São Domingos & Sim & 8 & 3,12 \\
\hline $7^{\circ}$ & Campo Erê & Sim & 6 & 2,53 \\
\hline $8^{\circ}$ & Ipuaçu & Não & 4 & 2,00 \\
\hline $9^{\circ}$ & Jupiá & Não & 1 & 1,74 \\
\hline $10^{\circ}$ & $\begin{array}{c}\text { São Lourenço do } \\
\text { Oeste }\end{array}$ & Sim & 10 & 1,56 \\
\hline
\end{tabular}

Fonte: Do autor. 
Revista Científica do Corpo de Bombeiros Militar de Pernambuco

XVIII Seminário Nacional de Bombeiros - Foz do Iguaçu PR

Vol.04 No11 - Edição Especial XVIII SENABOM - ISSN 2359-4829

Versão on-line disponível em: http://www.revistaflammae.com.

Para o $14^{\circ} \mathrm{BBM}$, observa-se um situação semelhante àquela do $12^{\circ} \mathrm{BBM}$, ou seja, ainda que haja alguns municípios com índices elevados, os números absolutos de óbitos por afogamento são, relativamente, baixos. Além do que, dentre os municípios listados, No $12^{\circ}$ e no $14^{\circ}$, há poucos com OBM.

Com base nos resultados supracitados, verificou-se que os municípios catarinenses mais propensos para uma intensificação das atividades preventivas relacionadas aos óbitos por afogamento são os seguintes:

Tabela 19: Municípios catarinenses mais propensos para uma intensificação das atividades preventivas relacionadas aos óbitos por afogamento.

\begin{tabular}{|c|c|}
\hline BBM & MUNICÍPIOS \\
\hline $1^{\circ}$ & Florianópolis \\
\hline $2^{\circ}$ & Tangará, Caçador, Campos Novos e Videira \\
\hline $3^{\circ}$ & Gaspar \\
\hline $4^{\circ}$ & Corre de Torres, Balneário Arroio do Silva e Balneário Rincão \\
\hline $5^{\circ}$ & Concórdia \\
\hline $6^{\circ}$ & Itapoá, Balneário Barra do Sul, São Francisco do Sul, Barra Velha, Penha, Garuva, Navegantes, \\
\hline $7^{\circ}$ & Balneário Piçarras e Itajaí \\
\hline $8^{\circ}$ & Jaguaruna, Laguna e Garopaba \\
\hline $9^{\circ}$ & Itaiópolis ${ }^{14}$ e Mafra \\
\hline $10^{\circ}$ & Governador Celso Ramos, Palhoça e Biguaçu \\
\hline $11^{\circ}$ & Piratuba e Herval d'Oeste \\
\hline $12^{\circ}$ & Sem prioridade \\
\hline $13^{\circ}$ & Bombinhas, Porto Belo, Balneário Camboriú, Itapema e Tijucas \\
\hline $14^{\circ}$ & Sem prioridade \\
\hline
\end{tabular}

Fonte: Do autor.

Considerando que, além dos municípios à cima listados, outros, que não ficaram entre os dez maiores índices relativos nos seus respectivos batalhões e que possuem quartéis, também apresentaram elevado número de óbitos absolutos, sugere-se que as atividades preventivas inerentes aos óbitos por afogamento também sejam destinadas

14 Único município listado no qual não há OBM. 
aos municípios de Blumenau, Içara, Araranguá, Lages, Chapecó, Guaramirim, Joinville, Jaraguá do Sul, Imbituba, Tubarão e São José.

\section{CONCLUSÕES}

Retomando-se o problema inicial desta pesquisa foram identificados os 35 municípios catarinenses mais vulneráveis aos óbitos por afogamento, considerando os seus respectivos índices relativos e absolutos e a possibilidade de intervenção preventiva do CBMSC nos mesmos. Quanto aos objetivos específicos, a classificação dos 295 municípios catarinenses quanto ao índice relativo de óbitos por afogamento no período estudado pode ser verificada através do link já citado ao longo do estudo, sendo que, destes, 57 cidades apresentaram índice igual ou superior a 5.

Analisando os resultados por regiões, o grau de vulnerabilidade aumenta no sentido leste-oeste; analisando-os por BBBBMM, destacam-se o $7^{\circ}, 13^{\circ}$ e $8^{\circ}$ BBM no litoral e o $11^{\circ} \mathrm{BBM}$, no interior do Estado. Por sua vez, ao analisar-se cada município, verificou-se que, estando ou não na região litorânea, há uma grande variação no índice relativo das cidades catarinenses. Neste sentido, mesmo com um trabalho preventivo intensificado na região litorânea durante o período de verão, chama a atenção os elevados índices de boa parte dos municípios localizados à beira-mar. Por sua vez, a situação dos municípios do interior vai ao encontro do título desta pesquisa. Quanto ao dez municípios com os maiores índices relativos de cada batalhão, verificou-se que, em muitos casos, obteve-se números elevados em virtude da baixa população dos mesmos, o que, de certo modo, não os torna tão vulneráveis aos casos em questão. Neste sentido, ao relacionar os índices relativos dos municípios tabelados com os números absolutos de casos e com os municípios aonde há quartel do CBMSC, foram definidos, para cada BBM, os municípios catarinenses mais propensos para uma intensificação das atividades preventivas relacionadas aos óbitos por afogamento. Destes 35 municípios o desafio maior fica voltado para aqueles nos quais o efetivo BM destinado somente ao SAT. 


\section{Revista FLAMMAE}

Revista Científica do Corpo de Bombeiros Militar de Pernambuco

XVIII Seminário Nacional de Bombeiros - Foz do Iguaçu PR

Vol.04 No11 - Edição Especial XVIII SENABOM - ISSN 2359-4829

Versão on-line disponível em: http://www.revistaflammae.com.

Como proposta para a redução destes índices, sugere-se a intensificação de ações preventivas do CBMSC nestes municípios, buscando (I) colocar em prática o Curso de Formação de Guarda-vidas Mirim, em conformidade com a Portaria Nr 2-2018 do CBMSC e seus anexos, a qual Regula os Currículos de Cursos e Programas de Matérias e Planos de Unidade Didáticas das atividades de ensino na Educação Continuada do CBMSC (CBMSC, 2018a) e (II) sinalizar através da colocação de placas, os locais mais perigosos para ocorrências de afogamento os locais públicos utilizados como ambientes aquáticos para lazer, não guarnecidos pelo serviço de Guarda-vidas, de acordo com a sinalização dos ambientes aquáticos apresentada na Lição 9 (Coordenação do serviço) do Curso de Formação de Guarda-vidas Militar (CBMSC, 2018c).

Quanto às sugestões para trabalhos futuros, ratifica-se a importância em (I) verificar-se especificamente, como se dão os casos de óbitos por afogamento em cada município, analisando-os ano a ano e (II) realizar estudo para identificar a cidade de origem das vítimas de arrastamento, afogamento e afogamentos seguidos de morte ocorridos no litoral, buscando-se realizar trabalho preventivo também neste sentido.

\section{REFERÊNCIAS}

ASSOCIAÇÃO DOS BOMBEIROS VOLUNTÁRIOS NO ESTADO DE SANTA CATARINA (ABVESC). Corporações. Disponível em: http://www.abvesc.com.br/. Acesso em: 13 de novembro de 2018.

ARAUJO, Rodrigo Thadeu. Aspectos médicos legais e preventivos dos casos de afogamento na região de Ribeirão Preto. Dissertação (Mestre em Ciências Médicas Patologia Experimental) - Faculdade de Medicina de Ribeirão Preto, Universidade de São Paulo. Ribeirão Preto, 2007. 60p.

BMJ Best Practice. Drowning. The right clinical information, right where it's needed. Nov 09, 2017.

CORPO DE BOMBEIROS MILITAR DE SANTA CATARINA (CBMSC). Estado Maior Geral. BM-2 (informações). Florianópolis, 2017. 
Revista Científica do Corpo de Bombeiros Militar de Pernambuco XVIII Seminário Nacional de Bombeiros - Foz do Iguaçu PR

Vol.04 N011 - Edição Especial XVIII SENABOM - ISSN 2359-4829

Versão on-line disponível em: http://www.revistaflammae.com.

Comando-Geral do CBMSC. Separata ao Boletim Nr 11-2017. Portaria Nr 244-17-CBMSC. Redefinir e baixar para conhecimento da corporação a articulação do $5^{\circ}$ Batalhão de Bombeiros Militar, que desativa o $7^{\circ} \mathrm{PBM} / 3^{\mathrm{a}} \mathrm{CBM} / 5^{\circ} \mathrm{BBM}$ (Ibirama SAT), subordinando o $1^{\circ} \mathrm{GBM} / 7^{\circ} \mathrm{PBM} / 3^{\mathrm{a}} \mathrm{CBM} / 5^{\circ} \mathrm{BBM}$ (Ibirama - SAT - Previsto), o $2^{\circ} \mathrm{GBM} / 7^{\circ} \mathrm{PBM} / 3^{\mathrm{a}} \mathrm{CBM} / 5^{\circ} \mathrm{BBM}$ (Vitor Meireles - Previsto) e $\mathrm{o}$ $3^{\circ} \mathrm{GBM} / 7^{\circ} \mathrm{PBM} / 3^{\mathrm{a}} \mathrm{CBM} / 5^{\circ} \mathrm{BBM}$ (José Boiteux - Previsto), diretamente ao $6^{\circ} \mathrm{PBM} / 3^{\mathrm{a}} \mathrm{CBM} / 5^{\circ} \mathrm{BBM}$ (Presidente Getúlio) conforme os Apêndices 1 e 2 do ANEXO da presente Portaria. Florianópolis, 8 de junho de 2017.

. Comando-Geral do CBMSC. Portaria Nr 2-18-CBMSC. Regula os Currículos de Cursos e Programas de Matérias e Planos de Unidade Didáticas das atividades de ensino na Educação Continuada do CBMSC. Florianópolis, 27 de fevereiro de 2018.

. Manual de Salvamento Aquático. Lição 6 - Recuperação de Afogados. Curso de Formação de Soldados (CFSd). CBMSC, 2018.

Manual de Salvamento Aquático. Lição 9 - Coordenação do serviço. Curso de Formação de Soldados (CFSd). CBMSC, 2018.

FISCHER JÚNIOR, Remaclo; SOUZA, Edson Carvalho de; MAIA, João Roberto. Afogamento em água salgada e doce: estudo de 10 casos com revisão bibliográfica. Monografia (Graduação em Medicina) - Universidade Federal de Santa Catarina UFSC. Florianópolis, 1982. 49p.

INSTITUTO BRASILEIRO DE GEOGRAFIA E ESTATÍSTICA (IBGE). Cidades. Disponível em: $<$ https://cidades.ibge.gov.br/brasil/sc/panorama $>$. Acessado em: $4 \mathrm{dez}$. 2017.

JOSÉ. Rafael Manoel \& KAFFER, Everton Kleinubing. Mapa de Santa Catarina identificando o índice relativo de óbitos por afogamento em cada município do Estado desde o dia $1^{\circ}$ de janeiro de 1989 até 31 de dezembro de 2015. Fraiburgo, 2018.

SOMMARIVA, Delpho Thiago Muniz. Estudo epidemiológico de óbitos por afogamento na região da grande Florianópolis de 1991 a 2005. Monografia (Graduação em Medicina) - Universidade Federal de Santa Catarina - UFSC. Florianópolis, 2006. 41p.

SZPILMAN, David. Afogamento - Boletim epidemiológico no Brasil. Sociedade Brasileira de Salvamento Aquático (SOBRASA). Disponível em:

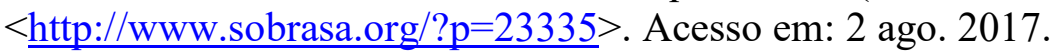

